\title{
Electrocardiographic abnormalities in patients presenting with strokes
}

\author{
G. TOMKIN, R. P. K. COE, AND JOHN MARSHALL1 \\ From the West Middlesex Hospital and the Institute of Neurology, Queen Square, London, W.C.I
}

The development of changes in the electrocardiogram during the acute phase of cerebrovascular lesions is a well-recognized phenomenon. Burch, Meyers, and Abildskov (1954) defined these changes as typically consisting of inversion of the $T$ waves, which were of considerable amplitude and width, in standard and chest leads, prolongation of the QTc interval and the presence of $U$ waves. They encountered these abnormalities in cases of subarachnoid haemorrhage, intracerebral haemorrhage, and cerebrovascular accidents of non-specified type. Subsequently, the changes were also reported in cases of head injury (Hersch, 1961) and meningitis and space-occupying lesions (Hersch, 1964).

Shuster (1960) examined the heart at necropsy in three patients with a cerebrovascular accident who had shown these ECG changes during life and found it to be normal. Koskelo, Punsar, and Sipilä (1964), on the other hand, found subendocardial haemorrhages in their three cases of subarachnoid haemorrhage and suggested these were the cause of the ECG changes. However, there have been many case reports, of which Russell (1966) has supplied a thorough recent review, in which the heart was normal, hence subendocardial haemorrhage cannot be invoked as the cause of the ECG changes in all cases. Cropp and Manning (1960) observed the development of the ECG changes during manipulation of the orbital surface of the frontal lobe of the brain during the approach to an anterior cerebral aneurysm and suggested that they arose from area 13, which subserves autonomic function. The present study was undertaken to test this hypothesis and to elucidate the clinical problem which arises when ECG changes are encountered in a patient with a stroke.

\section{METHODS}

A series of 85 consecutive patients admitted to hospital with an acute stroke formed the basis of the study. There were 30 males and 55 females; the age range of the males was from 54 to 86 years with a mean of 62.9 and of the females 32 to 93 years with a mean of $70 \cdot 6$.

${ }^{1}$ To whom, at the Institute, requests for reprints should be sent.
An electrocardiogram with standard, unipolar, and chest leads was recorded soon after admission and blood taken for estimation of the electrolytes and the serum glutamic oxaloacetic transaminase (SGOT) and hydrooxybutyric dehydrogenase (HBD) in all cases. Urine was collected for estimation of the catecholamines in the first 12 cases, but as these were normal and collection difficult this was discontinued.

Twenty of the patients died, 17 having shown ECG abnormalities. The brain was removed in all 17 and after fixation in $10 \%$ formalin, the cerebral vessels were dissected and the brain sectioned in $1 \mathrm{~cm}$ coronal slices (Dr. A. Knudsen). The heart was examined in only 16 of the cases as permission for examination of the brain onl $w$ was granted in one instance. The coronary arteries were o examined by longitudinal section and the heart them sectioned.

\section{RESULTS}

In this series of 85 cases of acute stroke the ECG was normal in only 13 . The remaining 72 showe ECG abnormalities of various kinds, the frequency of which is given in Table $\mathrm{I}$.

The largest group comprised the 57 cases showing ECG evidence of ischaemia indicated by inverted $\mathrm{T}$ waves in the standard leads and in leads over the left ventricle and displacement of the S-T segment. There were no abnormal $Q$ waves in this group. Eleven of this group died, the brain being examined in all, the heart in 10; the findings are presented in Table II. There was fibrosis of the myocardium in six, incompetence of the mitral valve in two, and the heart was normal in two. In the brain there was extensive infarction of one hemisphere including the orbital surface of the frontal lobe in five, small areas

TABLE I

\begin{tabular}{lccc}
\multicolumn{4}{c}{ FREQUENCY } \\
Evidence of: & ECG & ABNORMALITIES & \\
\hline ischaemia & Survived & Died & Total \\
recent infarct & 46 & 11 & 57 \\
old infarct & -6 & 1 & 1 \\
bundle branch block & 2 & 4 & 10 \\
heart block (Grade II) & - & - & 2 \\
paroxysmal atrial fibrillation & 1 & -1 & 1 \\
& 55 & 17 & 72
\end{tabular}


TABLE II

NECROPSY FINDINGS IN CASES WITH ECG EVIDENCE OF ISCHAEMIA

\begin{tabular}{|c|c|c|c|c|}
\hline C.V. No. & Sex & Age & Heart & Brain \\
\hline 1012 & $\mathbf{F}$ & 80 & Extensive fibrosis & $\begin{array}{l}\text { Infarction right internal capsule } \\
\text { Thrombosis right and left internal carotid arteries }\end{array}$ \\
\hline 1009 & $\mathbf{F}$ & 60 & Moderate fibrosis & $\begin{array}{l}\text { Massive infarct anterior two-thirds right hemisphere } \\
\text { Thrombosis right middle cerebral artery }\end{array}$ \\
\hline $\begin{array}{l}1016 \\
1007\end{array}$ & $\begin{array}{l}\mathbf{M} \\
\mathbf{M}\end{array}$ & $\begin{array}{l}86 \\
68\end{array}$ & $\begin{array}{l}\text { Moderate fibrosis } \\
\text { Mitral incompetence }\end{array}$ & $\begin{array}{l}\text { Infarct left parietal region } \\
\text { Haemorrhage right hemisphere from plane of the genu of the corpus collosum to occipital } \\
\text { lobe }\end{array}$ \\
\hline $\begin{array}{l}1019 \\
1020\end{array}$ & $\mathbf{F}$ & $\begin{array}{l}81 \\
78\end{array}$ & $\begin{array}{l}\text { Extensive fibrosis } \\
\text { Fibrosis left ventricle }\end{array}$ & $\begin{array}{l}\text { Severe stenosis of basilar artery-no infarct } \\
\text { Infarct anterior two-thirds right hemisphere } \\
\text { Thrombosis right middle cerebral artery }\end{array}$ \\
\hline 1022 & $\mathbf{F}$ & 84 & Mitral incompetence & $\begin{array}{l}\text { Massive infarct anterior two-thirds of left hemisphere } \\
\text { Occlusion left internal carotid artery }\end{array}$ \\
\hline 1006 & $\mathbf{F}$ & 73 & Fibrosis left ventricle & $\begin{array}{l}\text { Infarct right fronto-parietal region } \\
\text { Thrombosis right middle cerebral artery }\end{array}$ \\
\hline 1008 & $\mathbf{F}$ & 84 & Normal & $\begin{array}{l}\text { Infarct } 2 \times 1.5 \times 1.5 \mathrm{~cm} \text { in left internal capsule } \\
\text { Severe generalized atheroma }\end{array}$ \\
\hline $\begin{array}{l}1018 \\
1005\end{array}$ & $\begin{array}{l}\mathbf{M} \\
\mathbf{F}\end{array}$ & $\begin{array}{l}54 \\
80\end{array}$ & $\begin{array}{l}\text { Normal } \\
\text { Not examined }\end{array}$ & $\begin{array}{l}\text { Haemorrhage } 4 \times 2 \times 4 \mathrm{~cm} \text { in left occipital pole } \\
\text { Infarct anterior two-thirds left hemisphere } \\
\text { Thrombosis left internal carotid artery }\end{array}$ \\
\hline
\end{tabular}

of infarction not involving this area in three, haemorrhage, again sparing this area, in two, and no infarction in one.

There was one patient whose ECG showed evidence of a recent myocardial infarction (Table I); necropsy confirmed this and revealed no cerebral lesion beyond atheroma of vessels; this was the only case in which the serum HBD was raised to 640 units, the levels in the remaining cases being within the normal range.

Of the 10 cases in whom ECG showed evidence of old myocardial infarction, four died, the presence of an old infarct being confirmed at necropsy in three. These had a right fronto-parietal haemorrhage, a small infarct of the left internal capsule, and a large infarct of the anterior two-thirds of the left hemisphere respectively. In the fourth case the heart proved to be normal; in the brain there was a subcortical haemorrhage in the left hemisphere extending $6 \mathrm{~cm}$ back from the plane of the genu of the corpus callosum and displacing the mid-line structures $2.5 \mathrm{~cm}$ to the right.

Two patients showed left bundle branch block and one paroxysmal atrial fibrillation, but none came to necropsy. The one patient with Grade II heart block died, and necropsy revealed severe atheroma of the coronary arteries, and, in the brain, an anterior communicating aneurysm which had ruptured into the ventricle.

\section{DISCUSSION}

This study has confirmed that cerebrovascular accidents may be associated with changes in the ECG suggestive of myocardial ischaemia, in cases in which on pathological examination there is no evidence of myocardial ischaemia. The lack of pathological change in the heart could not have been due to an insufficient time having elapsed between a supposed infarction and death, as all the patients survived for at least 24 hours. The study has not confirmed the suggestion that the ECG changes are due to involvement of area 13 on the orbital surface of the frontal lobe (Cropp and Manning, 1960). One of the two cases in this series in which the heart was normal had a small infarct in the region of the left internal capsule, the other a haemorrhage in the left occipital pole, both well away from area 13. Melville, Blum, Shister, and Silver (1963) produced $T$ wave inversion and displacement of the S-T segment by hypothalamic stimulation in cats, particularly by stimulating the lateral nuclei of the hypothalamus. Lesions in any part of the brain may by distortion of mid-line structures, disturb the hypothalamus. Subarachnoid haemorrhage and head injury may also do this by producing vasospasm, especially of the penetrating arteries. It is therefore possible that the ECG changes suggestive of ischaemia, which occur in cerebral lesions in the presence of a normal heart, are due to disturbance of the hypothalamus.

Although ECG changes suggestive of myocardial ischaemia occur in the presence of a normal heart in patients with acute cerebrovascular lesions, the present study has shown that the changes are more likely to indicate myocardial damage than not. In only two of the 11 cases that came to necropsy was the heart normal; the remainder had serious cardiac disease. Heron and Anderson (1965) recently reported five patients who presented with a stroke in whom a painless myocardial infarction was demonstrated electrocardiographically, and Acheson and Hutchinson (1964) found electrocardiographic evidence of myocardial ischaemia in a considerable 
proportion of patients with transient ischaemia attacks and completed strokes. In the present series 72 of the 85 patients $(84 \%)$ showed ECG evidence of myocardial damage, the presence of a cardiac lesion being confirmed in 13 of the 16 patients $(81 \%)$ in whom the heart was examined at necropsy.

The situation is therefore quite different from that of the young patient with subarachnoid haemorrhage from a ruptured berry aneurysm, in whom changes in the $\mathrm{S}-\mathrm{T}$ segment and $\mathrm{T}$ waves are unlikely to indicate myocardial damage. The old patient with a stroke and similar ECG changes is likely to have a myocardial lesion. This fact must be borne in mind in planning surgery in the former, and in the treatment, and especially the rehabilitation, of the latter.

\section{SUMMARY}

The ECG was abnormal in 72 out of 85 consecutive patients presenting with a stroke. Three of the 17 patients with ECG abnormalities who came to necropsy had normal hearts, but in none was area 13 on the orbital surface of the frontal lobe involved. The remaining 14 had myocardial damage. In older patients with stroke, ECG abnormalities are more likely than not to indicate myocardial damage.
We would like to express our thanks to Dr. A. Knudsen for the necropsy findings. This work was part of the $Z$ studies of cerebrovascular disease supported by a grant $\stackrel{\mathbb{}}{\subset}$ from the British Heart Foundation to one of us (J.M.)

\section{REFERENCES}

Acheson, J., and Hutchinson, E. C. (1964). Observations on the natural history of transient cerebral ischaemia. Lancet, 2, 871- $\Omega$ 874.

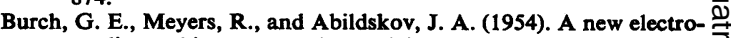
cardiographic pattern observed in cerebrovascular accidents. Circulation, 9, 719-723.

Cropp, G. J., and Manning, G. W. (1960). Electrocardiographic changes simulating myocardial ischaemia and infarction associated with spontaneous intracranial hemorrhage. Ibid., 22, $\mathrm{C}$ 23-38.

Heron, J. R., and Anderson, E. G. (1965). Concomitant cerebral and $\frac{\bar{D}}{\bar{\omega}}$ cardiac ischaemia. Lancet, 2, 405-407.

Hersch, C. (1961). Electrocardiographic changes in head injury. $\mathbb{D}$ Circulation, 23, 853-860.

- (1964). Electrocardiographic changes in subarachnoid haemorrhage, meningitis, and intracranial space-occupying lesions. Brit. Heart J., 26, 785-793.

Koskelo, P., Punsar, S., and Sipilä, W. (1964). Subendocardial haemorrhage and ECG changes in intracranial bleeding. $\vec{\omega}$ Brit. med. J., 1, 1479-1480.

Melville, K. I., Blum, B., Shister, H. E., and Silver, M. D. (1963). Cardiac ischemic changes and arrhythmias induced by hypothalamic stimulation. Amer. J. Cardiol., 12, 781-791.

Russell, A. S. (1966). The association of subarachnoid haemorrhage with an abnormal electrocardiogram and acute pulmonary oedema. Guy's Hosp. Rep., 114, 463-474.

Shuster, S. (1960). The electrocardiogram in subarachnoid haemo rhage. Brit. Heart J., 22, 316-320. 